\title{
EFEKTIVITAS LAYANAN FOTOKOPI SEBAGAI PENGGANTI PEMINJAMAN KOLEKSI BAGI PEMUSTAKA LUAR UPT PERPUSTAKAAN UNTAN
}

\author{
Eka Putri Anjarwati, Sisilya Saman Madeten. \\ Program Studi D-3 Perpustakaan FKIP Untan Pontianak \\ email: ekaputrianjarwati@untan.com
}

\begin{abstract}
The main problem in this final task is that there are still outside leaders who do not know not allowed to borrow collections but can only photocopy and read on the spot. The purpose of this study is to find out the effectiveness of photocopying services as a substitute for collectible lending for UPT Untan library. The type of research used is descriptive research with a quantitative approach. The respondents numbered 17 people from various students of Universities / Institutes / Higher Schools in Pontianak and some even came from universities outside West Kalimantan. The data was collected using a questionnaire in the form of a Google Document link distributed through WhatsApp. Based on the results of data analysis using SPSS version 18 showed that the results of the questionnaire validity test were declared valid because it exceeded the signification level $r$ calculated greater than the $r$ table and with reliability test results declared reliable because $0.905>0.60$. While the results of the calculation of the effectiveness of the service using the percentage of interpretation of the score based on intervals obtained the number $72.5 \%$ which means effective.
\end{abstract}

Keywords : Effectiveness, Photocopying Services, Outside Library

\section{PENDAHULUAN}

Dalam Undang-undang Republik
Indonesia No. 43 Tahun 2007 Tentang
Perpustakaan, Perpustakaan merupakan
sebuah institusi pengelola koleksi karya tulis,
karya cetak, dan/karya rekam secara
profesional dengan sistem baku guna
memenuhi kebutuhan pendidikan, penelitian,
pelestarian, informasi dan rekreasi para
pemustaka. Dalam hal ini, perpustakan
menjadi pusat informasi dengan segudang
koleksi yang dimiliki untuk memenuhi
kebutuhan pemustaka melalui layanan yang
diberikan. Layanan untuk mengakses koleksi
perpustakaan dinamakan lananan
perpustakaan. Layanan ini diberikan agar
pemustaka dapat dengan mudah
menggunakan koleksi sesuai kebutuhan.

Sejalan dengan bertambahnya kebutuhan informasi dan wawasan baru dikalangan masyarakat luas akibat dari globalisasi perrpustakaan dituntut untuk dapat menyesuaikan diri dengan memberikan layanan yang bersifat aktif, cepat, dan tepat dalam memenuhi kebutuhan informasi pengguna.Jadi, hakikat layanan perpustakaan itu sendiri adalah kegiatan penyediaan jasa yang cepat dan tepat dalam memberikan kemudahan bagi pemustaka dalam mengakses dan mengunakan koleksi perpustakaan yang ada.

Setiap perpustakaan memiliki jenis layanan yang berbeda menyesuaikan dengan kondisi perpustakaan, ditinjau dari besar kecilnya ruangan, jumlah koleksi yang tersedia di perpustakaan, sarana prasarana pendukung layanan dan pastinya jenis layanan dari perpustakaan tersebut.Layanan 
sirkulasi, layanan referensi, layanan terbitan berkala, layanan fotokopi merupakan contoh layanan yang ada di perpustakaan. 
Untuk layanan peminjaman dan pengembalian koleksi serta referensi semua jenis perpustakaan sudah menerapkan karena merupakan layanan utama di perpustakaan. Sedangkan untuk layanan lainnnya menyesuaikan dengan kesiapan dari perpustakaan dalam menyediakan sarana dan prasarana serta petugas yang memahami cara kerja layanan tersebut. Contohnya seperti layanan fotokopi yang memerlukan sarana mesin fotokopi dan teknisi atau petugas.

Layananfotokopi disediakan agar pemustaka yang tidak dapat atau tidak ingin meminjam koleksi tersebut untuk dibawa pulang, dapat memfotokopinya diperpustakaan. Layanan ini juga dapat meningkatkan keterpakaian koleksi yang tidak dapat dipinjamkan. Dengan adanya layanan ini maka pemanfaatan koleksi dapat lebih optimal karena bagi pemustaka yang bukan anggota perpustakaan dan tidak dapat meminjam koleksi yang dibutuhkan, tetap dapat membawa hasil fotokopinya untuk di bawa pulang meski tidak semua halaman dokumen dapat di fotokopi (Rahayu,2014:1.15) .

Layananfotokopi biasanya dimanfaatkan perpustakaan perguruan tinggi yang dimana memiliki pemustaka beragam berasal dari perguruan lain yang membutuhkan koleksi perpustakaan sebagai sumber informasi. Tidak semua pemustaka perpustakaan perguruan tinggi dapat meminjam koleksi hanya pemustaka dari perguruan tinggi tersebut saja yang boleh meminjam. Bagi pemustaka luar perpustakaan perguruan tinggi hanya dapat membaca ditempat dan memanfaatkan layanan fotokopi untuk mendapatkan koleksi yang diinginkan.

UPT Perpustakaan Untan merupakan salah satu perpustakaan perguruan tinggi yang menyediakan layanan fotokopi. Adapun koleksi yang dapat difotokopi seperti buku dan hasil karya ilmiah Untuk hasil karya ilmiah tidak semua dapat dapat difotokopi secara fulltext melainkan hanya beberapa saja karena untuk melindungi hak cipta karya tersebut. Sedangkan untuk buku pemustaka dibebaskan untuk jumlah fotokopinya. Layanan ini dimanfaatkan oleh pemustaka luar UPT Perpustakaan Untan yang tidak dapat meminjam koleksi namun membutuhkan informasi pada koleksi tersebut.Adapun koleksi yang tidak boleh dipinjam yaitu buku teks, karya ilmiah, terbitan berkala serta sumber-sumber informasi lain.

Berdasarkan pengamatan yang dilakukan peneliti, masih ada pemustaka luar yang belum mengetahui jika tidak diperbolehkan meminjam koleksi. Pada awalnya pemustaka diperbolehkan untuk meminjam namun dikarenakan ada beberapa yang tidak dikembalikan maka diberlakukan hanya boleh memfotokopi untuk mendapatkan informasi yang dibutuhkan.Selain itu, tidak ada pemberitahuan tertulis mengenai pemustaka luar hanya dapat membaca ditempat dan memfotokopi koleksi untuk mendapatkan informasi yang dibutuhkan. Sehingga ada beberapa pemustaka yang sudah menemukan buku yang akan dipinjam, pada saat akan melakukan proses peminjaman tidak diperbolehkan hal ini seringkali membuat para pemustaka tidak mendapatkan informasi yang dibutuhkan. Dengan mengkaji informasi yang didapat penulis merasa tertarik untuk melakukan penelitian di UPT Perpustakaan Untan dengan judul "Efektivitas layanan fotokopi sebagai pengganti peminjaman koleksi bagi pemustaka luar UPT Perpustakaan Untan".

Dari analisis pengamatan yang didapatkan maka penelitian ini bertujuan Untuk mengetahui efektivitas dari layanan fotokopi di UPT Perpustakaan Untan sebagai pengganti peminjaman koleksi bagi pemustaka luar.

\section{METODE PENELITIAN}

Pada penelitian ini, peneliti menggunakan penelitian deskriptif dengan pendekatan kuantitatif. 
Data primer berasal dari pemustaka luar UPT Perpustakaan UNTAN yang berjumlah 17 orang serta kepala perpustakaan dan pustakawan lantai 3 layann referensi.berupa informasi tertulis yang biasanya didapatkan dari instansi atau tempat penelitian. Selain itu, terdapat pula literatur-literatur yang diguanakan untuk mendukung penelitian.

Penelitian dilaksanakan pada bulan April-Juli 2021 yang berlokasi di UPT Perpustakaan Untan, Jln. Prof Dr. H. Hadari Nawawi, Bansir Laut, Kecamatan Pontianak Tenggara, Kota Pontianak, Kalimantan Barat.

Teknik pengambilan sampel yang digunakan yaitu Purposive sampling.Kriteria responden yang dibutuhkan yaitu pemustaka luar dari UPT Perpustakaan Untan, yang terdaftar sebagai anggota serta yang sudah pernah memfotokopi koleksi.Responden yang dapatkan berjumlah 17 orang dan sudah memenuhi kriteria yang dibutuhkan.Responden berasal dari mahasiswa perguruan tinggi ataupun institusi yang ada di Pontianak bahkan ada beberapa yang berasal dari luar Pontianak.

Adapun teknik pengumpulan data pada penelitian ini adalah observasi, dokumentasi serta kuesioner atau angket.Skala pengukuran angket yang ini yaitu skala Likert dengan bentuk jawaban berupa pilihan ganda.Angket/kuesioner penelitian tidak dicetak melainkan berbentuk Link Google Document yang dapat diakses melalui Chrome atau mesin pencari lainnya menggunakan Handphone, laptop ataupun PC.

\section{Tabel 1 Skor Penilaian Angket}

\begin{tabular}{lc}
\hline \multicolumn{1}{c}{ Pendapat } & Skor $(\mathbf{S})$ \\
\hline Tidak efektif & 1 \\
\hline Kurang efektif & 2 \\
\hline Efektif & 3 \\
\hline Sangat efektif & 4 \\
\hline Instrumen pada penelitian ini terdiri da
\end{tabular}

telepon genggam atau smartphone sebagai alat bantu dokumentasi dan penyebaran angket dalam bentuk link, kertas atau buku yang berisi panduan observasi serta alat tulis seperti pulpen.

Teknik analisis data pada penelitian ini yaitu:

1. Uji Validitas

2. Uji Realibialitas

3. Statistik Deskriptif

Adapun langkah-langkah analisis deskriptif meliputi (Cholilah, 2013:8-9):
a. Pengumpulan data responden
b. Pengolahan data.
c. Penyajian data.
d. Analisis data.

\section{HASIL PENELITIAN DAN PEMBAHASAN}

\section{Hasil}

Berdasarkan apa yang telah dipaparkan peneliti, adapun tujuan dari penelitian ini yaitu untuk mengetahui efektivitas dari layanan fotokopi yang ada di UPT Perpustakaan Untan sebaga pengganti peminjaman koleksi bagi pemustaka luar. Adapun bentuk dari penelitian ini yaitu penelitian kuantitatif dengan metode pengumpulan data menggunakan kuesioner yang dibagikan pada responden yang berjumlah 17 yang sudah memenuhi kriteria yang dibutuhkan.

1. Uji validitas

Uji validitas adalah salah satu pengujian data yang digunakan untuk mengetahui ketepatan atau kecermatan dari suatu instrumen penelitian. Pengujian validitas menggunakan program SPSS Statistic 18, dengan menguji 20 pertanyaan mengenai efektivitas layanan fotokopi. Berdasarkan hasil uji validitas jika perhitungan lebih besar atau sama dengan taraf signifikan maka dinyatakan valid. Jadi dari semua pertanyaan mengenai efektivitas layanan fotokopi dapat dinyatakan valid karena telah melebihi taraf signifikasi $r_{\text {hitung }}$ lebih besar dari $r$ tabel. 
Tabel 2Uji Validitas

\begin{tabular}{|c|c|c|c|}
\hline \multirow[b]{2}{*}{ Pertanyaan } & \multicolumn{3}{|c|}{ Nilai } \\
\hline & $\begin{array}{l}\text { Nilai } \\
\mathbf{r}_{\text {Tabel }}\end{array}$ & $\begin{array}{c}\mathbf{r} \\
\text { Hitung }\end{array}$ & $\begin{array}{c}\text { Keterang } \\
\text { an }\end{array}$ \\
\hline 1 & 0.482 & 0.507 & VALID \\
\hline 2 & 0.482 & 0.579 & VALID \\
\hline 3 & 0.482 & 0.544 & VALID \\
\hline 4 & 0.482 & 0.559 & VALID \\
\hline 5 & 0.482 & 0.581 & VALID \\
\hline 6 & 0.482 & 0.629 & VALID \\
\hline 7 & 0.482 & 0.595 & VALID \\
\hline 8 & 0.482 & 0.688 & VALID \\
\hline 9 & 0.482 & 0.658 & VALID \\
\hline 10 & 0.482 & 0.583 & VALID \\
\hline 11 & 0.482 & 0.640 & VALID \\
\hline 12 & 0.482 & 0.549 & VALID \\
\hline 13 & 0.482 & 0.547 & VALID \\
\hline 14 & 0.482 & 0.651 & VALID \\
\hline 15 & 0.482 & 0.821 & VALID \\
\hline 16 & 0.482 & 0.695 & VALID \\
\hline 17 & 0.482 & 0.527 & VALID \\
\hline 18 & 0.482 & 0.626 & VALID \\
\hline 19 & 0.482 & 0.547 & VALID \\
\hline 20 & 0.482 & 0.565 & VALID \\
\hline
\end{tabular}

2. Uji reliabilitas

Tabel 3Uji Reliabilitas

\begin{tabular}{cc}
\multicolumn{2}{c}{ Reliability Statistics } \\
\hline $\begin{array}{c}\text { Cronbach's } \\
\text { Alpha }\end{array}$ & N of Items \\
\hline .905 & 20 \\
\hline
\end{tabular}

Besar nilai reliabilitas instrumen yang didapatkan penelitian yaitu 0.905 , Jika dilihat dari standar nilai reliabilitas maka instrumen penelitian dinyatakan reliabel karena $0.905>0.60$.

3. Perhitungan efektivitas

Sebelum masuk pada perhitungan peneliti akan memaparkan pengelompokkan responden yang nantinya digunkan pada perhitungan.

a. Pengelompokkan responden pertama yaitu berdasarkan jenis kelamin. Responden dengan jenis kelamin laki-laki yang menjawab kuesioner berjumlah 4 orang atau 23,5\% sedangkan responden perempuan berjumlah 13 orang atau $76,4 \%$ yang mana lebih jelasnya dapat pula dilihat dari tabel dibawah ini:

Tabel 4Responden berdasarkan jenis kelamin

\begin{tabular}{lccc}
\hline No. & $\begin{array}{c}\text { Jenis } \\
\text { kelamin }\end{array}$ & Frekuensi & Persentase \\
\hline 1. & Laki-laki & 4 & $23,5 \%$ \\
\hline 2. & Perempuan & 13 & $76,4 \%$ \\
\hline & Total & $\mathbf{1 7}$ & $\mathbf{1 0 0 \%}$
\end{tabular}

b. Responden Berdasarkan Program Studi/Jurusan

Berdasarkan program studi/jurusan,responden berasal dari ilmu ekonomi, manajemen, MKP, pendidikan bahasa dan sastra, $\mathrm{P}$. TIK, PGSD, teknik mesin, teknik informatika, ilmu keperawatan, manajemen/ekonomi serta pendidikan bahasa inggris.

Tabel 5Responden berdasarkan program studi/jurusan

\begin{tabular}{llcc}
\hline No. & $\begin{array}{c}\text { Program } \\
\text { studi/jurusan }\end{array}$ & $\begin{array}{c}\text { Frekuen } \\
\text { si }\end{array}$ & $\begin{array}{c}\text { Persent } \\
\text { ase }\end{array}$ \\
\hline 1. & Ekonomi & 1 & $5,8 \%$ \\
\hline 2. & Ilmu ekonomi & 1 & $5,8 \%$ \\
\hline 3. & Ilmu & 2 & $11,7 \%$ \\
& keperawatan & & \\
\hline 4. & Manajemen & 1 & $5,8 \%$ \\
\hline 5. & Manajemen/Ek & 3 & $17,6 \%$ \\
& onomi & & \\
\hline 6. & MKP & 1 & $5,8 \%$ \\
\hline 7. & Pendidikan & 1 & $5,8 \%$ \\
& bahasa dan & & \\
& sastra & & \\
\hline 8. & Pendidikan & 3 & $17,6 \%$ \\
\hline
\end{tabular}




\begin{tabular}{|c|c|c|c|}
\hline \multicolumn{4}{|c|}{ bahasa inggris } \\
\hline 9. & P. TIK & 1 & $5,8 \%$ \\
\hline 10. & PGSD & 1 & $5,8 \%$ \\
\hline 11. & $\begin{array}{l}\text { Teknik } \\
\text { informatika }\end{array}$ & 1 & $5,8 \%$ \\
\hline 12. & Teknik mesin & 1 & $5,8 \%$ \\
\hline & Jumlah & 17 & $100 \%$ \\
\hline c. & $\begin{array}{l}\text { Responden } \\
\text { Institut/Sekolah }\end{array}$ & inggi/ U & $\begin{array}{l}\text { erdasarkan } \\
\text { iversitas }\end{array}$ \\
\hline & $\begin{array}{l}\text { Tabel } 6 \text { Respond } \\
\text { astitut/sekolah ti }\end{array}$ & $\begin{array}{l}\text { a berdas } \\
\text { ggi/Univ }\end{array}$ & $\begin{array}{l}\text { rkan } \\
\text { rsitas }\end{array}$ \\
\hline No. & $\begin{array}{l}\text { Institut/sekol } \\
\text { ah } \\
\text { tinggi/univers } \\
\text { itas }\end{array}$ & $\begin{array}{c}\text { Frekue } \\
\text { nsi }\end{array}$ & $\begin{array}{c}\text { Persenta } \\
\text { se }\end{array}$ \\
\hline 1. & $\begin{array}{l}\text { IKIP PGRI } \\
\text { Pontianak }\end{array}$ & 5 & $29.4 \%$ \\
\hline 2. & $\begin{array}{l}\text { Poltekkes } \\
\text { Kemenkes } \\
\text { Pontianak }\end{array}$ & 1 & $5.8 \%$ \\
\hline 3. & STIEP & 1 & $5.8 \%$ \\
\hline 4. & $\begin{array}{l}\text { Universitas } \\
\text { Brawijaya } \\
\text { Malang }\end{array}$ & 1 & $5.8 \%$ \\
\hline 5. & $\begin{array}{l}\text { Universitas } \\
\text { Gajah Mada }\end{array}$ & 1 & $5.8 \%$ \\
\hline 6. & $\begin{array}{l}\text { Universitas } \\
\text { Jember }\end{array}$ & 1 & $5.8 \%$ \\
\hline 7. & $\begin{array}{l}\text { Universitas } \\
\text { Muhammadiya } \\
\text { h Pontianak }\end{array}$ & 5 & $29.4 \%$ \\
\hline 8. & $\begin{array}{l}\text { Universitas } \\
\text { Sarjanawiyata }\end{array}$ & 1 & $5.8 \%$ \\
\hline
\end{tabular}

\begin{tabular}{|c|c|c|c|}
\hline 9. & \multicolumn{3}{|l|}{ Tamansiswa } \\
\hline \multirow[t]{3}{*}{9.} & Universitas & 1 & $5.8 \%$ \\
\hline & \multicolumn{3}{|l|}{ Widya } \\
\hline & \multicolumn{3}{|l|}{ Dharma } \\
\hline & Jumlah & 17 & $100 \%$ \\
\hline
\end{tabular}

Dari tabel 6 didapatkan bahwa pengelompokkan responden yang ketiga berasal dari IKIP PGRI Pontianak, Universitas Muhammadiyah Pontianak, Poltekkes Kemenkes Pontianak, STIEP, Universitas Brawijaya Malang, Universitas Gajah Mada, Universitas Jember, Universitas Sarjanawiyata serta Universitas Widya Dharma.

Untuk mengetahui apakah layanan fotokopi efektif sebagai pengganti peminjaman koleksi, peneliti menggunakan beberapa perhitungan. Yang pertama yaitu menghitung jumlah jawaban kuesioner yang diberikan dalam bentuk rekapitulasi berdasarkan skor penilaian angket.

Tabel 4Perhitungan Keseluruhan Jawaban Responden

\begin{tabular}{lccc}
\hline Penilaian & $\begin{array}{c}\text { Skor } \\
(\mathbf{S})\end{array}$ & $\begin{array}{c}\text { Frekuensi } \\
(\mathbf{F})\end{array}$ & $\begin{array}{c}\text { Jumlah } \\
(\mathbf{S}) \mathbf{x}(\mathbf{F})\end{array}$ \\
\hline $\begin{array}{l}\text { Tidak } \\
\text { efektif }\end{array}$ & 1 & 24 & 24 \\
\hline $\begin{array}{l}\text { Kurang } \\
\text { efektif }\end{array}$ & 2 & 49 & 98 \\
\hline Efektif & 3 & 151 & 453 \\
\hline $\begin{array}{l}\text { Sangat } \\
\text { efektif }\end{array}$ & 4 & 103 & 412 \\
\hline \multicolumn{1}{c}{ Total } & & $\mathbf{3 2 7}$ & $\mathbf{9 8 7}$ \\
\hline
\end{tabular}

Pada Tabel 4 hasil rekapitulasi didapatkan pengkategorian skor berdasarkan pada rentang skor ideal dimana:

1. Jumlah skor maksimal diperoleh dari

$=$ Skor tertinggi $\mathrm{x}$ jumlah item pertanyaan jumlah responden

$=4 \times 20 \times 17$

$=1.360$ 
2. Jumlah skor minimal diperoleh dari

$=$ Skor terendah $\mathrm{x}$ jumlah item pertanyaan $\mathrm{x}$ jumlah responden

$=1 \times 20 \times 17=340$.

Selain itu, pada Tabel 2 juga diperoleh nilai total dari setiap jaewaban responden sebesar 327 yang digambarkan dalam bentuk frekuensi sedangkan untuk jumlah keseluruhan apabila dikalikan dengan item setiap skor maka sebesar 987.

Untuk mengetahui apakah data yang didapat menunjukkan efektif atau tidak sebuah layanan dapat diketahui dengan melakukan interpretasi perhitungan berdasarkan interval.Adapun rumus untuk menghitung interpretasi skor penilaian berdasarkan interval yaitu (Hamid, 2019:96):

$$
\begin{aligned}
\text { Rumus Indeks } \%= & \frac{\text { Total Skor }}{\text { Y Skor Maksimal }} \times 100 \\
= & \frac{987}{1360} \times 100 \\
& =72,5 \%
\end{aligned}
$$

Dari perhiutngan diatas jika dicocokkan dengan kriteria interpretasi skor berdasarkan interval menurut Cholilah (2013) yang dimana:

1. Nilai interval0-20\% = Sangat (Tidak setuju/Tidak puas/Buruk/Kurang sekali)

2. Nilai interval21-40\% $=$ Tidak setuju/Tidak puas/Kurang baik

3. Nilai interval $41-60 \%=$ Cukup puas/Cukup setuju/Netral

4. Nilai interval $61-80 \%=$ Setuju/Baik/Puas/Suka

5. Nilai interval $81-100 \%=$ Sangat (Setuju/Baik/Puas/Suka)

Angka 72,5\% masuk pada interval 61$80 \%$ yang dimana berarti sebagian besar responden menjawab setuju bahwa layanan fotokopi dapat digunakan sebagai pengganti peminjaman koleksi bagi pemustaka luar
UPT Perpustakaan Untan. Sedangkan 27,5\% menjawab tidak efektif.

\section{Pembahasan}

Dari hasil penelitian yang dilakukan peneliti terlihat bahwa layanan fotokopi efektif sebagai pengganti peminjaman koleksi bagi pemustaka luar di UPT Perpustakaan Untan. Yang mana dari hasil perhitungan menunjukkan besar nilai persentase berada di interval $61-80 \%$.

Layanan fotokopi sendiri ialah salah satu fasilitas pendukung diperpustakaan yang memudahkan pemustaka dalam melakukan penggandaan dokumen, penjilidan, laminating dan penyedian ATK (alat tulis kerja). Bagi pemustaka luar sebuah perpustakaan, layanan fotokopi menjadi cara yang efektif dalam mendapatkan informasi yang dibutuhkan. Hal ini dikarenakan ada beberapaperpustakaan yang tidak memperbolehkan pemustaka luar untuk meminjam koleksi yang ada. Tentunyasebuah perpustakaan memiliki alasan yang kuat mengapa tidak memperbolehkan meminjam koleksinya, salah satunya koleksi yang dipinjamkan jarang dikembalikan.

UPT Perpustakaan Untan adalah salah satu contoh perpustakaan yang tidak memperbolehkan pemustaka luar untuk meminjam koleksi yang ada melainkan hanya dapat membaca ditempat dan memfotokopi agar informasi yang dibutuhkan bisa dibawa pulang.Pada awalnya pemustaka luar diperbolehkan untuk meminjam koleksi namun dikarenakan ada beberapa yang tidak mengembalikan maka diberlakukan hanya boleh memfotokopi saja.

Layanan fotokopi UPT Perpustakaan Untan tidak hanya dapat digunakan oleh pemustaka luar melainkan seluruh pemustaka yang ada dengan tujuan menggandakan informasi ataupun keperluan administrasi yang berhubungan dengan perpustakaan.Adapun koleksi yang boleh difotokopi yaitu buku umum dan karya ilmiah.Untuk buku umum tidak ada batasan 
jumlah yang boleh difotokpi sedangkan karya ilmiah seperti tugas akhir, skripsi dan tesis hanya boleh difotokopi maksimal 3 skripsi pada BAB 1 dan 2. Sedangkan Bab metode penelitian maksimal lima lembar.

Letak ruang layanan fotokopi berada di lantai yaitu tepatnya berhadapan dengan ruang pengolahan dan bersebelahan langsung dengan ruang tata usaha.

Rata-rata pemustaka luar yang memfotokopi koleksi perharinya 10 orang.Pemustaka luar yang sering memfotokopi koleksi dari kalangan mahasiswa dan dosen.Sedangkan staff ataupun siswa termasuk jarang.Adapun syarat untuk fotokopi koleksi yaitu kartu anggota perpustakaan bagi pemustaka luar dan kartu tanda mahasiswa bagi mahasiswa Universtas Tanjungpura.

Tata cara fotokopi koleksi di UPT Perpustakaan Untan bagi pemustaka luar ataupun dalam sama.

1. Pemustaka memilih koleksi yang akan difotokopi.

2. Bagi pemustaka luar yang ingin memfotokopi koleksi menunjukkan kartu anggota perpustakaan sedangkan mahasiswa dari Universitas Tanjungpura cukup menunjukkan kartu tand mahasiswa serta menyerahkan buku yang akan difotokopi.

3. Pemustaka menunjukkan bon serta buku yang akan difotkopi ke petugas layanan fotokopi dan membayar jumlah fotokopi sesuai dengan harga yang telah ditentukan (Rp 500 per lembar).

4. Buku yang telah selesai difotokopi dikembalikan lagi ke pustakawan agar disimpan ke rak.

Dalam melakukan kegiatan fotokopi ada hal yang perlu diperhatikan yaitu hak cipta dari koleksi tersebut.Menurut UU No. 28 Tahun 2014 menyebutkan bahwa Hak cipta ialah hak eksklusif dimiliki pencipta yang timbul secara otomatis berdasarkan prinsip deklaratif setelah suatu ciptaan diwujudkan dalam bentuk nyata tanpa mengurangi pembatasan sesuai peraturan perundang undangan.

$\begin{array}{ccc}\begin{array}{c}\text { Langkah } \\ \text { perpustakaan }\end{array} & \text { yang } & \text { dapat diambil } \\ \text { dalam } & \text { menghindari }\end{array}$ pelanggaran akibat hak cipta koleksi yaitu pemberlakuan aturan dalam melakukan fotokopi koleksi.Hal ini pula sudah diterapkan oleh UPT Perpustakaan Untan yang dimana untuk hasil karya ilmiah penelitian memiliki batasan dalam memfotokopi tidak diperbolehkan secara keseluruhan melainkan pada Bab-Bab tertentu.

\section{SIMPULAN DAN SARAN \\ Simpulan}

Berdasarkan hasil penelitian yang dilakukan, diperoleh kesimpulan bahwa efektif memfotokopi koleksi sebagai pengganti peminjaman koleksi khsusnya bagi pemustaka luar UPT Perpustakaan Untan. Hal ini dapat dilihat pada hasil perhitungan data pada kuesioner yang diberikan peneliti mengenai efektivitas layanan dimana total skor berjumlah 987 dengan besar nilai skor maksimal (4) yaitu 1.360 dan besar nilai skor minimal (1) berjumlah 340 . Sedangkan besar persentase pada interpretasi skor berdasarkan intervalnya yaitu $72,5 \%$ atau berarti efektif.

\section{Saran}

Adapun saran yang dapat peneliti berikan pada penelitian ini yaitu (1) Menyediakan informasi tercetak mengenai pemustaka luar yang tidak boleh meminjam koleksi melainkan hanya dapat membaca dan memfotokopi koleksi, (2) Menyediakan informasi tercetak mengenai tata cara memfotokopi koleksi, koleksi yang boleh difotokopi dan jumlah serta harga fotokopi perlembar (3) Diharapkan UPT Perpustakaan Untan mendata pemustaka yang pernah memfotokopi beserta koleksinya serta (4) Diharapkan UPT Perpustakaan Untan dapat mendigitalisasikan koleksi yang ada dengan memperhatikan aturan hak cipta koleksi sehingga mempermudah pemustaka yang 
tidak boleh meminjam namun tetap mendapatkan informasi yang dibutuhkan.

\section{DAFTAR RUJUKAN}

Cholilah, Yenta. (2013). Studi tentang efektivitas sistem pelayanan sirkulasi perpustakaan di kantor perpustakaan dan arsip kota Mojokerto. Jurnal Pendidikan Adaministrasi Perkantoran (JPAP). Vol. 1, No. 3., 8-9. https://jurnalmahasiswa.unesa.ac.i d/index.php/jpap/article/view/374

1 diakses pada tanggal 9 November 2021 pukul 09.00 WIB.

Hamid, Hasriani. Efektivitas layanan sirkulasi di perpustakaan Universitas Negeri Makassar.
Skripsi, Makassar. UIN Alauddin Makasar, 2019.

Rahayu, L., dkk. (2014). Layanan Perpustakaan. Tangerang Selatan: Universitas Terbuka.

Undang-undang Republik Indonesia No. 43 Tahun 2007 Tentang Perpustakaan https://www.perpusnas.go.id/lawdetail.php?lang=id\&id=17092011 4322Ir9g6HhRuc. Diakses pada tanggal 20 April 2021 pukul 09.30 WIB

Undang-undang Republik Indonesia No. 28 Tahun 2014 Tentang Hak cipta. https://peraturan.go.id/common/doku men/ln/2014/uu28-2014bt.pdf. Diakses pada tanggal 13 September 2021 pukul 14:18 WIB 